\title{
Simultaneous giant adrenocortical and renal cell carcinoma associated with lead exposure from residual gun pellets after shotgun injury: case report
}

\author{
Berislav Mazuran * (10) and Adelina Hrkac
}

\begin{abstract}
Background: A case of simultaneous adrenocortical and renal cell carcinoma due to long-term lead exposure from residual gun pellets is a rare and relatively unknown topic in the literature.

Case presentation: We present a 43-year-old male patient with a giant retroperitoneal tumor. Thirteen years before he had a shotgun injury of the left upper side of the abdomen and residual gun pellets are present in the abdominal wall. Extirpation of the tumor and the left kidney was performed. Histopathological examination described adrenocortical and renal cell carcinoma.

Conclusion: Continuous and long-term exposure to toxic lead effects from residual gun pellets and traumatic injury represent likely carcinogenic factors in the presented patient.
\end{abstract}

Keywords: Adrenocortical and renal cell carcinoma, Lead exposure, Case report

\section{Background}

Renal cell carcinoma (RCC) accounts for $2-3 \%$ of all adult malignant neoplasms. One of the possible environmental etiological factors for the development of RCCs described in the literature is lead compounds. Possible mechanisms for lead carcinogenesis are interference with DNA synthesis and repair. [1] Significant data are confirming that retained gun pellets raise lead concentrations in blood, but there is little literature on its possible long-term carcinogenic effects on those patients. [2] Adrenocortical carcinoma (ACC) is a rare malignancy and most of the patient with ACC are adults, with a slight female predominance.

The purpose of this case report is to present a patient who has been diagnosed with renal cell carcinoma and

*Correspondence: berislav.mazuran@yahoo.com

Department of Urology, Clinical Hospital "Sveti Duh", Sveti Duh 64, Zagreb, Croatia ipsilateral adrenocortical carcinoma at the site of a previous gunshot wound, thirteen years after injury, with remaining pellets in the tissue surrounding the kidney.

\section{Case presentation}

We present a 43-year-old male who attempted suicide in 2005, inflicting upon himself a wound to his upper left abdomen, followed by surgery, resulting in a partial colon resection due to injury. Some of the gun pellets were not extracted from the site.

Thirteen years later, he presented with fatigue, weight loss, and anemia. Mild pain in the left superior part of the abdomen was noticed; hematuria is not registered. Symptoms lasted for three months before a medical examination started. After a thorough examination and diagnostics were conducted, it was evident that he had a palpable mass under the lower left rib cage, on the same side as the previous gunshot wound. A CT scan was then performed which showed a huge tumorous mass, $21 \mathrm{~cm}$ 
in diameter, adjacent to the left kidney and remnants of gun pellets scattered around this area (Fig. 1). Open surgery was performed through the left thoracoabdominal incision with partial resection of the tenth rib, and complete extirpation of the tumor, including the kidney, was performed (Fig. 2). The pathological diagnosis was formulated as follows: "A sample, $24 \times 18 \times 13 \mathrm{~cm}$ in size, consists of a kidney, $12 \mathrm{~cm}$ in height, surrounded by fatty tissue, and a well-confined, irregular tumor, $12 \mathrm{~cm}$ in height. On the lower kidney part, there is a tumor, $5 \mathrm{~cm}$ in diameter, with histopathological characteristics of a renal clear cell carcinoma, Fuhrman grade 2. The tumor, positioned by the kidney, matches adrenocortical carcinoma, with vimentin, synaptophysin, and CD56 being diffusely positive, and inhibin and calretinin focally positive. EMA, CK, CK7, p-63, s-100, desmin, chromogranin
A, CD 10, CD34, CD 45 and CD 117 are negative" (Fig. 3). The postoperative course was complicated by a mild pancreatic leak at drainage, which spontaneously resolved during the hospitalization. The patient was discharged from the hospital in good physical condition. Blood lead concentration was tested after surgery, during follow-up and was $19 \mu \mathrm{g} / \mathrm{dL}$. One year after the surgery, on CT no local tumor recurrences or metastases are visible. Further oncological monitoring is carried out.

\section{Discussion}

The toxic effects of lead exposure are well known and documented in the literature. Prolonged exposure results in the accumulation of lead in the bones and kidneys. The association between lead exposure and renal tumors has been demonstrated in laboratory animals and in several
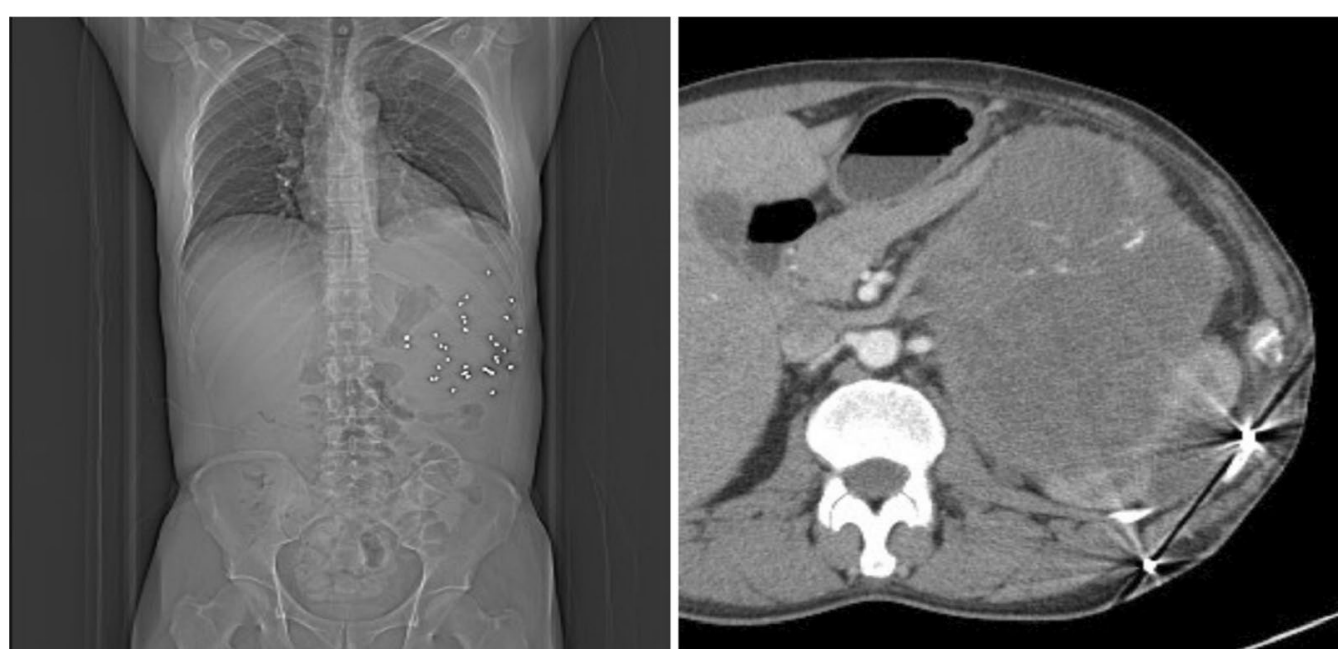

Fig. 1 Left: X-ray with remnant gun pellets. Right: CT scan with tumor and left kidney
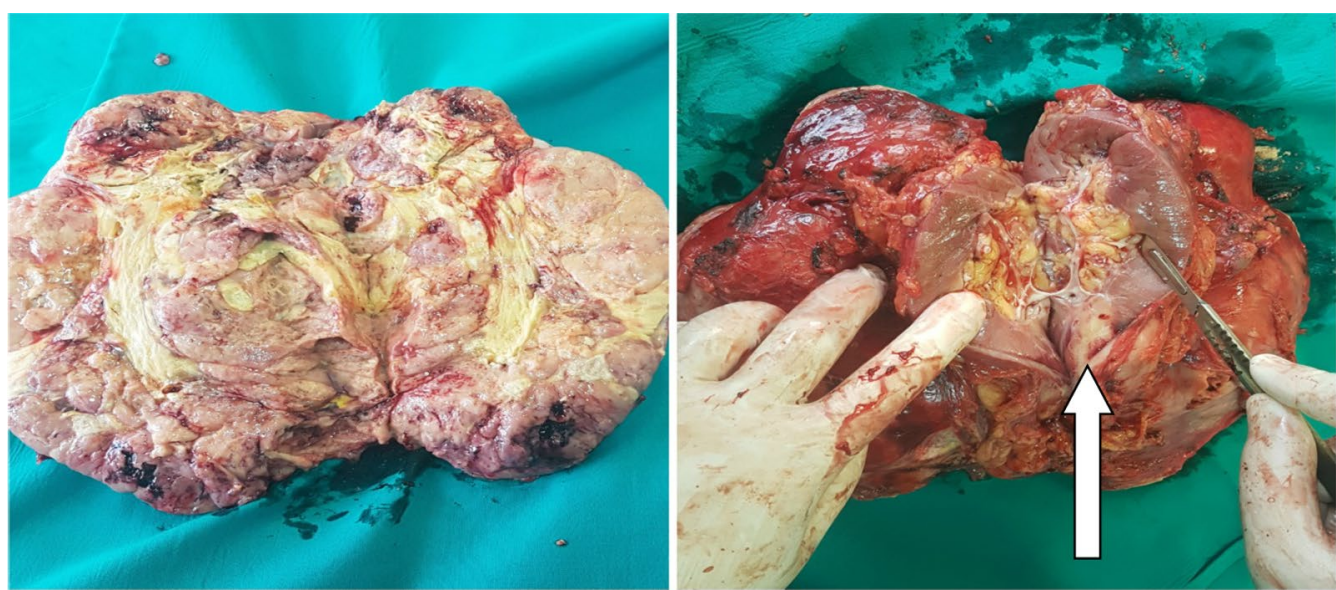

Fig. 2 Left: medial side of the tumor. Right: lateral side with kidney and tumor in lover pole arrow) 


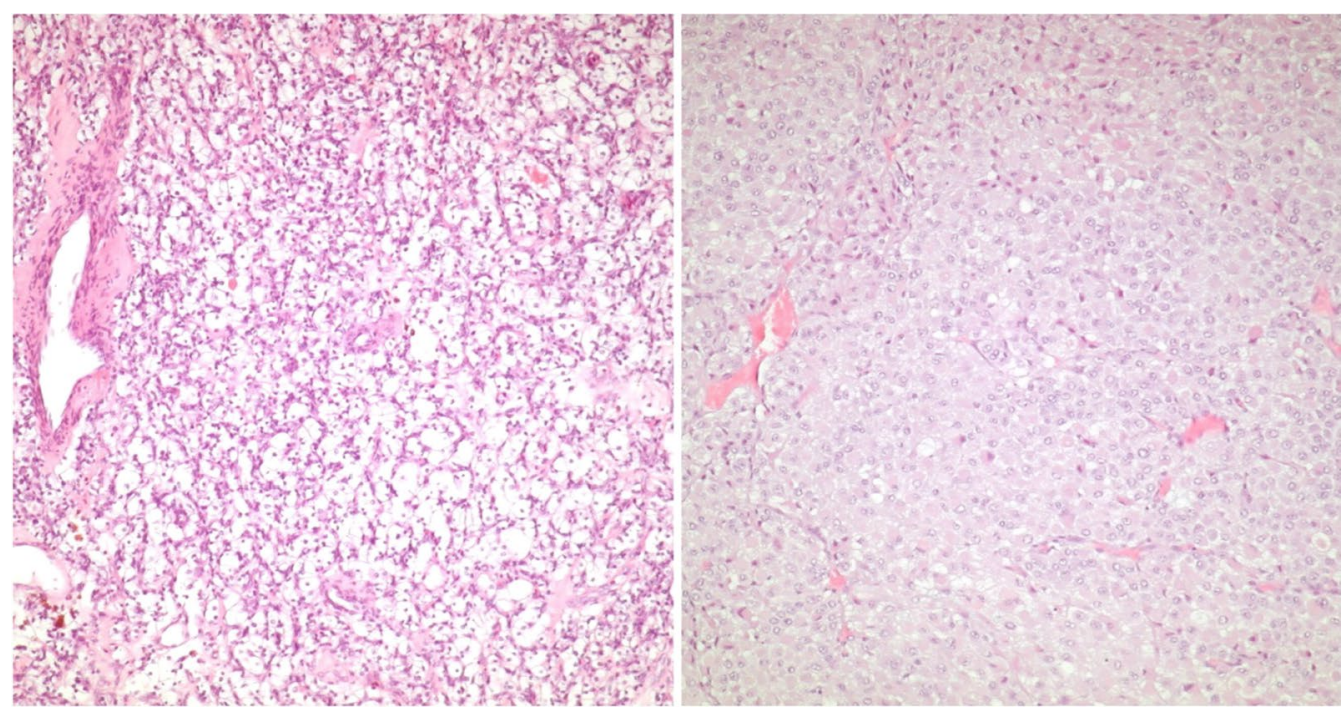

Fig. 3 Histopathology Left: renal cell carcinoma. Right: adrenocortical carcinoma

human studies [1] There are few case reports of tumors resulting from the long-term toxic lead effect from shotgun wounds such as oral carcinoma [3], and metastatic bronchial carcinoma. [4]. Retained bullet fragments can be the cause of systemic lead poisoning [5]. Long-term exposure and high levels of lead are the main risk factors for carcinogenesis. [1] Our patient has moderately high blood lead concentration and developed anemia as a systemic symptom. The organs that developed the tumors were surrounded by gun pellets (Fig. 1), so a local impact of the lead is also plausible. Simultaneous RCC and ACC have not been described often, so a rare case of concomitant tumors of that origin is presented in this article. Only one other case reported simultaneous homolateral renal and adrenal carcinoma [6]. When compared to similar case reports in the literature, the authors come to the conclusion that, in their best knowledge, this is a unique case of renal cell carcinoma with concomitant adrenocortical carcinoma emerging at the site of the shotgun wound with residual pellets, without previous pathology regarding the kidney or the adrenal gland.

\section{Conclusion}

Shotgun pellets, with toxic lead exposure, and previous traumatic injury, could be etiopathological factors for carcinogenesis, in this case of adrenocortical carcinoma associated with renal cell carcinoma. Meticulous exploration and extraction of lead fragments to the fullest possible extent after wounding, especially in young patients, are the main goals to prevent such cases.

\section{Abbreviations \\ RCC: Renal cell carcinoma; ACC: Adrenocortical carcinoma; CT: Computed tomography.}

\section{Authors contributions}

All authors contributed to the study conception and design. Material preparation, data collection and analysis were performed by B.M. and A.H. All authors read and approved the final manuscript.

\section{Funding}

No funding was received for conducting this study.

\section{Availability of data and material}

All patients data are available on Department of Urology, Clinical Hospital, "Sveti Duh", Zagreb, Sveti Duh 64, Croatia.

\section{Declarations}

Ethics approval and consent to participate

This research study was conducted retrospectively from data obtained for clinical purposes. We consulted Ethical Committee in Clinical Hospital "Sveti Duh" who determined that our study did not need ethical approval.

\section{Informed consent}

Informed consent was obtained from patient included in the study.

\section{Consent for publication}

Patients signed informed consent regarding publishing their data, and written copy is available for the journal.

\section{Competing interests}

The authors have no relevant financial or no-financial interests to disclose.

Received: 1 February 2021 Accepted: 11 July 2021

Published online: 19 July 2021

\section{References}

1. Silbergeld EK (2003) Facilitative mechanisms of lead as a carcinogen. Mutat Res 10;533(1-2):121-133. https://doi.org/10.1016/j.mrfmmm.2003. 07.010 
2. Weiss D, Tomasallo CD, Meiman JG, Alarcon W, Graber NM, Bisgard KM, Anderson HA (2017) Elevated blood lead levels associated with retained bullet fragments-United States 2003-2012. MMWR Morb Mortal Wkly Rep 10;66(5):130-133. https://doi.org/10.15585/mmwr.mm6605a2

3. Kühnel TV, Tudor C, Neukam FW, Nkenke E, Stockmann P (2010) Air gun pellet remaining in the maxillary sinus for 50 years: a relevant risk factor for the patient? Int J Oral Maxillofac Surg 39(4):407-411. https://doi.org/ 10.1016/j.jom.2009.10.021

4. Sonnenfeld ED, Medill EV (1953) A metastatic deposit from carcinoma of the bronchus at the site of a previous gun-shot wound. Guys Hosp Rep 102(4):368-370
5. Akhtar AJ, Funnye AS, Akanno J (2003) Gunshot-induced plumbism in an adult male. J Natl Med Assoc 95(10):986-990

6. Granados Loarca E, Chéchile G, Villavicencio Mavrich H (1990) Simultaneous homolateral renal and adrenal carcinoma. Arch Esp Urol 43(8):909-911

\section{Publisher's Note}

Springer Nature remains neutral with regard to jurisdictional claims in published maps and institutional affiliations.

\section{Submit your manuscript to a SpringerOpen ${ }^{\circ}$ journal and benefit from:}

- Convenient online submission

- Rigorous peer review

- Open access: articles freely available online

- High visibility within the field

- Retaining the copyright to your article

Submit your next manuscript at $\boldsymbol{\nabla}$ springeropen.com 